\title{
PROFIL GANGGUAN NEUROKOGNITIF PADA PENDERITA PENYAKIT PARKINSON DI RUMAH SAKIT RUJUKAN DI KOTA DENPASAR TAHUN 2018
}

\author{
Putri Eka Pradnyaning ${ }^{1}$, Ketut Widyastuti ${ }^{1}$, Anak Agung Ayu Putri Laksmidewi ${ }^{1}$, Sri Yenni \\ Trisnawati ${ }^{1}$, DPG Purwa Samatra ${ }^{1}$, I Ketut Sumada ${ }^{2}$
}

${ }^{I}$ Departemen Neurologi, FK Universitas Udayana/RSUP Sanglah, Denpasar, Bali, Indonesia

${ }^{2}$ Departemen Neurologi, RSUD Wangaya, Denpasar, Bali, Indonesia

Diterima 20 Desember 2019

Disetujui 25 Januari 2020

Publikasi 30 Januari 2020

Korespondensi: putri.eka.pradnyaning@gmail.com
Cara merujuk artikel ini: Pradnyaning (et al). 2020. Profil Gangguan Neurokognitif pada Penderita Penyakit Parkinson di Rumah Sakit Rujukan di Kota Denpasar Tahun 2018. Callosum Neurology Journal 3(1): 22-29. DOI: https://doi.org/10.29342/cnj.v3i1.105

\section{ABSTRAK}

Latar Belakang: Gangguan fungsi kognitif memiliki dampak besar pada kualitas hidup penderita Penyakit Parkinson (PP), menambah beban pengampu dan biaya kesehatan. Tujuan: Untuk mengetahui prevalensi dan profil gangguan neurokognitif penderita PP berdasarkan demografis, gejala PP, dan domain kognitif yang terganggu.

Metode: Penelitian ini adalah penelitian deskriptif potong lintang terhadap 47 penderita PP rawat jalan di RS rujukan Kota Denpasar.

Hasil: Angka kejadian gangguan neurokognitif pada pasien PP di RS rujukan Kota Denpasar sebesar 55.3\% dengan distribusi terbanyak pada laki-laki (72.3\%), usia $\geq 60$ tahun
(63.8\%), pendidikan perguruan tinggi atau sederajat $(44.7 \%)$, dan pensiunan $(21.3 \%)$. Domain yang terganggu adalah eksekutif (48.9\%), memori (46.8\%), visuospasial $(29.8 \%)$, atensi $(23.4 \%)$, dan bahasa $(10.6 \%)$. Simpulan: Lebih dari setengah penderita PP rawat jalan di RS rujukan Kota Denpasar mengalami gangguan neurokognitif dengan karakteristik lakilaki, usia lebih dari 60 tahun, berpendidikan tinggi, dan pensiunan. Gangguan eksekutif merupakan domain neurokognitif yang paling banyak didapatkan. Kata Kunci: penyakit parkinson, gangguan neurokognitif, prevalensi

\begin{abstract}
Background: Impaired cognition has a major impact on quality of life, increasing caregiver burden, and health expense in patients with Parkinson Disease (PD).

Purpose: To determine the prevalence and profile of neurocognitive impairments in PD patients based on demographic, PD symptoms, and impaired cognitive domain.

Method: This study was a descriptive cross-sectional study measured 47 PD outpatients in referral hospitals in Denpasar.

Result: The occurance rate of neurocognitive impairment in PD patients in referral hospital in Denpasar was 55.3\%, the highest neurocognitive impairment group were male

(72.3\%), $\geq 60$ years old $(63.8 \%)$, university graduate $(44.7 \%)$, and retired $(21.3 \%)$. Domain disturbed were executive (48.9\%), memory (46.8\%), visuospatial (29.8\%), attention (23.4\%), and language (10.6\%).

Conclusion: More than half PD outpatients in referral hospital in Denpasar has neurocognitive impairment. Males, more than 60 years old, university graduates, and retired were dominating. Executive disturbance was the most neurocognitive disorders found.

Keywords: Parkinson's Disease, neurocognitive impairment, prevalence
\end{abstract}




\section{Latar Belakang}

Penyakit Parkinson (PP) pertama kali dideskripsikan oleh James Parkinson pada tahun 1817. Penyakit ini merupakan penyakit kronis, progresif, serta memiliki gejala motorik yang khas berupa tremor, bradikinesia, rigiditas, dan instabilitas postural. ${ }^{1}$ Belakangan setelah melalui eksplorasi yang panjang, diketahui bahwa PP tidak hanya berupa gejala motorik saja, tetapi juga memiliki gejala-gejala non motorik. Gejala-gejala non motorik pada PP yaitu gangguan fungsi kognitif, disfungsi sistem otonom, disfungsi sensorik, dan gangguan tidur., ${ }^{2,3}$

Fungsi kognitif merupakan aktivitas mental yang dilakukan secara sadar, misalnya berpikir, mengingat, belajar, dan menggunakan bahasa. Secara objektif fungsi kognitif dapat dinilai dengan menggunakan beberapa alat diagnosis baku, dan kemudian dapat dikelompokkan sesuai domain fungsi kognitif. ${ }^{4}$ Gangguan fungsi kognitif merupakan salah satu gejala non motorik yang paling sering ditemukan pada penderita PP. Gangguan fungsi kognitif pada penderita PP dapat berkisar antara gangguan fungsi kognitif ringan atau Parkinson's Disease Mild Cognitive Impairment (PD-MCI) hingga gangguan fungsi kognitif berat berupa Parkinson's Disease Dementia (PDD). ${ }^{3,5}$

Gangguan fungsi kognitif memiliki dampak yang besar pada kualitas hidup penderita PP, menambah beban pengampu, dan menambah biaya kesehatan yang dibutuhkan. Menurut beberapa penelitian longitudinal, diketahui bahwa 25 hingga $50 \%$ penderita PP akan menjadi PD-MCI atau berkembang dari PD-MCI ke PDD setelah 5 tahun terdiagnosis, dan sekitar 80\% akan menjadi PDD selama perjalanan penyakitnya. ${ }^{5-7}$ Penelitianpenelitian komunitas lain mendapatkan insiden PDMCI sebesar 20-60\%, dan 10\% dari PD-MCI ini akan menjadi PDD tiap tahunnya., ${ }^{3,8}$ Jika dibandingkan dengan orang seusianya, penderita Penyakit Parkinson memiliki risiko 3 hingga 6 kali lebih besar menderita demensia. ${ }^{5}$ Di Indonesia, data nasional mengenai gangguan fungsi kognitif pada penderita PP tidak banyak didapatkan, tetapi beberapa pusat pendidikan di Indonesia mendapatkan prevalensi gangguan fungsi kognitif pada penderita PP berkisar antara 20\% hingga
70\%. ${ }^{10-12}$ Menurut Watson dan Leverenz (2010) domain gangguan fungsi kognitif yang terganggu pada PP terutama adalah fungsi eksekutif, diikuti oleh gangguan atensi, memori, visuospasial, dan bahasa. $^{13}$

Data karakteristik gangguan fungsi neurokognitif pada PP di Indonesia, khususnya Bali, masih sangat minim, sehingga diperlukan penelitian dasar mengenai karakteristik gangguan fungsi kognitif pada PP di Bali. Kota Denpasar sendiri memiliki Fasilitas Kesehatan Tingkat Lanjutan (FKTL) tingkat 2 berupa RSUD Wangaya Denpasar dan FKTL tingkat 3 berupa RSUP Sanglah Denpasar sebagai rumah sakit rujukan penderita PP. Penelitian ini dilakukan di rumah sakit rujukan di Denpasar sehingga diharapkan dapat mencerminkan kondisi gangguan kognitif pada PP di seluruh Bali pada khususnya, dan Indonesia pada umumnya. Tujuan penelitian ini adalah untuk mengetahui prevalensi dan profil gangguan neurokognitif penderita PP di rumah sakit (RS) rujukan Kota Denpasar berdasarkan demografis, gejala PP, dan domain kognitif yang terganggu.

\section{Metode Penelitian}

Penelitian ini merupakan penelitian observasional deskriptif menggunakan rancangan penelitian deskriptif potong lintang (descriptive cross sectional) dimana semua penderita rawat jalan PP di poliklinik RSUP Sanglah dan RSUD Wangaya Denpasar yang memenuhi kriteria inklusi akan dinilai fungsi neurokognitifnya dengan menggunakan alat ukur MoCA-Ina dan dimasukan sebagai sampel penelitian. Populasi terjangkau penelitian ini adalah penderita PP dengan gangguan neurokognitif yang menjalani perawatan di Poliklinik Neurologi RSUP Sanglah dan RSUD Wangaya Denpasar bulan September hingga Desember 2018. Kriteria inklusi ialah: (1) penderita dengan Penyakit Parkinson; (2) penderita yang bersedia menjadi responden; (3) penderita bisa berkomunikasi secara verbal menggunakan Bahasa Indonesia. Kriteria eksklusi adalah: (1) penderita memiliki gangguan berbahasa berat seperti afasia atau disartria berat, gangguan penglihatan, dan gangguan pendengaran; (2) penderita tidak kooperatif; (3) memiliki komorbiditas yang berpotensi mempengaruhi fungsi kognitif seperti 
penyakit serebrovaskular, tumor otak, gangguan hati atau ginjal yang berat, dan riwayat trauma kepala yang menyebabkan penurunan kesadaran atau opname. Pengambilan sampel dilakukan dengan metode sampling nonrandom jenis consecutive. Sampel yang memenuhi kriteria inklusi dan eksklusi akan dinilai karakteristiknya. Data yang diperoleh ditabulasi dan diolah menggunakan program SPSS versi 21 untuk mendapatkan hasil penelitian. Penelitian ini sudah dinyatakan layak etik oleh Komisi Etik Fakultas Kedokteran Universitas Udayana.

\section{Hasil Penelitian}

Pada penelitian ini didapatkan 47 subjek yang memenuhi kriteria dan kemudian dapat diolah datanya. Subjek yang didapat dari FKTL 3 sebesar $63.8 \%$, sementara subjek yang didapatkan di FKTL 2 sebesar $27.7 \%$. Dari keseluruhan data didapatkan angka kejadian gangguan neurokognitif pada penderita PP yang menjalani perawatan di RS rujukan di Kota Denpasar adalah sebesar 55.3\%.

Profil dasar subjek penelitian dikelompokkan berdasarkan faktor demografis yaitu usia, jenis kelamin, pendidikan, dan pekerjaan. Profil dasar subjek dibagi menjadi profil dasar keseluruhan subjek penderita PP yang terlibat dan profil dasar subjek yang mengalami gangguan neurokognitif. Profil tersebut disajikan secara lengkap pada Tabel 1. Subjek penelitian juga dikelompokkan berdasarkan karakteristik PP yang diderita subjek, disajikan pada Tabel 2.

Tabel 1. Profil demografis subjek penelitian

\begin{tabular}{|c|c|c|c|c|}
\hline \multirow[t]{2}{*}{ Profil Demografis } & \multicolumn{2}{|c|}{ Total } & \multicolumn{2}{|c|}{ Gangguan Kognitif } \\
\hline & Jumlah & Presentase (\%) & Jumlah & Presentase (\%) \\
\hline $\begin{array}{l}\text { Rerata Umur } \pm \text { Standar Deviasi } \\
\text { (tahun) }\end{array}$ & \multicolumn{2}{|c|}{$63.85 \pm 8.68$} & \multicolumn{2}{|c|}{$66.35 \pm 8.33$} \\
\hline \multicolumn{5}{|l|}{ Kelompok Umur } \\
\hline$<60$ tahun & 17 & 36.2 & 7 & 26.9 \\
\hline$\geq 60$ tahun & 30 & 63.8 & 19 & 73.1 \\
\hline \multicolumn{5}{|l|}{ Jenis Kelamin } \\
\hline Laki-laki & 34 & 72.3 & 18 & 69.2 \\
\hline Perempuan & 13 & 27.7 & 8 & 30.8 \\
\hline \multicolumn{5}{|l|}{ Pendidikan } \\
\hline Tidak tamat SD & 2 & 4.3 & 2 & 7.7 \\
\hline $\mathrm{SD}$ & 9 & 19.1 & 7 & 26.9 \\
\hline SMP & 6 & 12.8 & 5 & 19.2 \\
\hline SMA & 9 & 19.1 & 4 & 15.4 \\
\hline Akademi/PT & 21 & 44.7 & 8 & 30.8 \\
\hline \multicolumn{5}{|l|}{ Pekerjaan } \\
\hline Tidak bekerja & 5 & 10.6 & 4 & 15.4 \\
\hline Pensiunan & 10 & 21.3 & 5 & 19.2 \\
\hline Petani/Buruh & 6 & 12.8 & 4 & 15.4 \\
\hline Swasta & 11 & 23.4 & 6 & 23.1 \\
\hline Wiraswasta & 4 & 8.5 & 2 & 7.7 \\
\hline PNS & 9 & 19.1 & 3 & 11.5 \\
\hline Lain-lain & 2 & 4.3 & 2 & 7.7 \\
\hline
\end{tabular}

*SD=Sekolah Dasar, SMP=Sekolah Menengah Pertama, SMA=Sekolah Menengah Atas, PT=Perguruan Tinggi, PNS=Pegawai Negeri Sipil 
Tabel 2. Karakteristik subjek penelitian berdasarkan profil gejala parkinson

\begin{tabular}{lcccc}
\hline \multirow{2}{*}{ Profil Gejala PP } & \multicolumn{2}{c}{ Total } & \multicolumn{2}{c}{ Gangguan Kognitif } \\
\cline { 2 - 5 } & Jumlah & Presentase (\%) & Jumlah & Presentase (\%) \\
\hline Onset Gejala Parkinson & 1 & & & \\
\hline$<6$ bulan & 10 & 2.1 & 5 & 3.8 \\
6 bulan -2 tahun & 17 & 36.2 & 9 & 19.2 \\
$2-5$ tahun & 19 & 40.4 & 11 & 34.6 \\
5 tahun & & & & 42.3 \\
\hline Stadium Hoehn and Yahr & 6 & 12.8 & 4 & \\
\hline 1 & 21 & 44.7 & 10 & 15.4 \\
2 & 16 & 34.0 & 8 & 38.5 \\
3 & 4 & 8.5 & 4 & 30.8 \\
4 & & & & 15.4 \\
\hline Gejala Motorik Dominan & 4 & 8.5 & 2 & 7.7 \\
Tremor 1 sisi & 11 & 23.4 & 7 & 26.9 \\
Tremor 2 sisi & 5 & 10.6 & 2 & 7.7 \\
Rigiditas 1 sisi & 8 & 17.0 & 4 & 15.4 \\
Rigiditas 2 sisi & 9 & 19.1 & 4 & 15.4 \\
Bradikinesia & 9 & 19.1 & 6 & 23.1 \\
Instabilitas postural & 1 & 2.1 & 1 & 3.8 \\
Lain-lain & & & & \\
\hline
\end{tabular}

*PP : Penyakit Parkinson

Gangguan neurokognitif subjek kemudian dikelompokkan berdasarkan domain kognitif yang terganggu. Status fungsional dicerminkan dengan activity daily living (ADL), di mana subjek yang mengalami gangguan dalam menjalankan ADL memerlukan bantuan dari orang-orang terdekat. Data profil gangguan neurokognitif dan status fungsional seluruh subjek tersaji pada Tabel 3.

Tabel 3. Profil gangguan neurokognitif responden

\begin{tabular}{lcc}
\hline Domain & Jumlah & Presentase \\
\hline Skor MoCA-INA & \multicolumn{2}{c}{$20.40 \pm 6.45$} \\
Atensi & 11 & 23.4 \\
Bahasa & 5 & 10.6 \\
Memori & 22 & 46.8 \\
Visuospasial & 14 & 29.8 \\
Fungsi Eksekutif & 23 & 48.9 \\
Activity Daily Living & 7 & 14.9 \\
(ADL) & & \\
\hline
\end{tabular}

*MoCA-INA: Montreal Cognitive Assessment Versi Indonesian

\section{Pembahasan}

Data demografis dasar keseluruhan subjek pada penelitian ini menunjukkan bahwa penderita PP di
RS rujukan di Denpasar lebih banyak pada lakilaki, usia dewasa lanjut ( $\geq 60$ tahun) dengan rerata umur 63 tahun, berpendidikan tinggi, dan bekerja di sektor formal. Hal ini sesuai dengan penelitianpenelitian sebelumnya yang mendapatkan bahwa usia merupakan faktor risiko utama terjadinya PP. Prevalensi dan insiden PP terus meningkat dan berbanding lurus dengan bertambahnya usia hingga mencapai puncak pada kelompok usia 80 tahun., ${ }^{2,4,15}$ Rasio pria : wanita pada PP diperkirakan mencapai 3:2, dengan awitan pada wanita diketahui pada usia lebih tua. Risiko menderita PP diketahui paling tinggi dimiliki oleh ras Hispanik, kemudian Kaukasia, Asia, dan orang kulit hitam. 2,14

Gambaran klinis klasik PP adalah gejala-gejala motorik yang dominan, sesuai dengan yang dideskripsikan oleh James Parkinson pada abad ke 19. Gejala motorik PP sendiri sangat heterogen dan bervariasi antar individu. Umumnya penderita akan mengeluhkan gejala yang unilateral, dan dalam perjalanan penyakitnya bisa didapatkan gejala yang relatif menetap ataupun berkembang menjadi bilateral dan diikuti dengan gejala-gejala motorik dan non motorik lainnya. ${ }^{14}$ Hampir separuh dari keseluruhan subjek pada penelitian ini telah 
menderita PP selama lebih dari 5 tahun, dengan derajat berat PP berupa stadium Hoehn and Yahr 2 . Gejala motorik dominan yang paling banyak ditemukan pada subjek penelitian ini adalah rigiditas 2 sisi.

Penelitian ini mendapatkan angka kejadian gangguan neurokognitif penderita PP yang menjalani perawatan di RS rujukan di Kota Denpasar sebesar 55.3\%. Beberapa penelitian serupa telah dilakukan di beberapa RS rujukan di Indonesia dan didapatkan hasil angka gangguan neurokognitif pada penderita PP sebesar 70.3\% di Makassar $^{10}$, 39\% di Manado ${ }^{11}$, dan 20\% di Malang ${ }^{12}$. Data mengenai prevalensi gangguan neurokognitif pada penderita PP secara nasional di Indonesia masih minim sehingga sulit dibandingkan.

Pada kelompok subjek yang menderita gangguan neurokognitif didapatkan profil demografis subjek didominasi oleh laki-laki usia dewasa lanjut $(\geq 60$ tahun) dengan rerata usia 66 tahun. Subjek dengan gangguan neurokognitif juga lebih banyak berpendidikan tinggi dan bekerja di sektor formal. Onset gejala PP pada kelompok subjek dengan gangguan neurokognitif paling banyak didapatkan lebih dari 5 tahun, dengan stadium Hoehn and Yahr 2, dan memiliki gejala motorik dominan saat pemeriksaan berupa rigiditas 2 sisi dan instabilitas postural. Karakteristik ini memiliki kesamaan dengan penelitian di Makassar, Manado, dan Malang yang mendapatkan gangguan neurokognitif pada penderita PP lebih banyak didapatkan pada laki-laki, rentang usia 60 hingga 80 tahun, berpendidikan SMA atau sederajat, dan merupakan pensiunan sektor formal. ${ }^{10-12}$

Penelitian kohort Deprenyl and Tocopherol Antioxidative Therapy of Parkinsonism (DATATOP) oleh Uc dkk. (2009) mendapatkan insiden gangguan kognitif pada penderita PP sebesar $2.4 \%$ pada 2 tahun pertama diagnosis PP ditegakkan dan $5.8 \%$ pada 5 tahun terdiagnosis. Rerata usia penderita gangguan kognitif pada penelitian ini adalah 61 tahun dengan stadium Hoehn and Yahr 1-3. Penderita yang mengalami gangguan fungsi kognitif dihubungkan dengan jenis kelamin laki-laki, usia yang lebih tua, gejala yang simetris, serta derajat berat gejala PP kecuali tremor. $^{16}$
Penelitian oleh Silalahi (2012) di RSUP Sanglah Denpasar mendapatkan hal yang cukup serupa, yaitu semakin tinggi stadium Hoehn and Yahr PP maka kemungkinan terjadinya gangguan kognitif makin besar pula. ${ }^{17}$ Penelitian oleh Huang dkk. (2015) di Taiwan menunjukkan menunjukkan sedikit kontradiksi, di mana insiden gangguan kognitif paling tinggi pada penderita PP adalah pada 6 bulan pertama terdiagnosis yaitu sebesar $11.98 \%$, dan insiden ini menurun tiap tahunnya menjadi $3.93 \%$ pada tahun pertama, $3.50 \%$ pada 3 tahun pertama, dan $2.20 \%$ pada tahun-tahun selanjutnya.18 Distribusi penderita PP pada penelitian ini lebih banyak didapatkan berada pada stadium Hoehn and Yahr 2, sehingga gangguan kognitif juga lebih banyak tampak pada kategori stadium tersebut.

Seperti pada gejala-gejala motorik, karakteristik gangguan fungsi kognitif pada PP bervariasi antar individu. Pada awalnya gangguan fungsi kognitif pada PP dianggap murni gangguan fungsi eksekutif akibat kurangnya dopamin pada jalur nigrostriatal, tetapi dalam perjalanannya seluruh domain kognitif dapat terganggu. ${ }^{19}$ Keterlibatan domain kognitif yang terganggu pada PP didapatkan tergantung dari waktu awitan penyakit dan progresivitas penyakit. Pola awal gangguan fungsi kognitif pada PP dipercaya berhubungan dengan proses patologis yang terjadi. ${ }^{20}$

Pada penelitian ini didapatkan gangguan fungsi eksekutif ditemukan pada 48.9\% dari keseluruhan subjek. Melihat patofisiologi gangguan fungsi kognitif pada PP yang melibatkan sirkuit prefrontal pada stadium awal, tidak mengherankan bila fungsi eksekutif merupakan gangguan yang paling awal dan paling sering ditemukan pada penderita PP. Gangguan fungsi eksekutif dapat dijumpai bahkan pada stadium pre-motorik. Pada beberapa penderita PP gangguan eksekutif bisa merupakan satusatunya gejala kognitif hingga akhir penyakitnya. ${ }^{13}$ Setelah fungsi eksekutif terganggu, gangguan yang selanjutnya dapat dijumpai pada penderita PP adalah visuospasial dan atensi yang berhubungan dengan sirkuit frontal eksekutif. ${ }^{20}$ Pada penelitian ini didapatkan gangguan atensi sebesar $23.4 \%$ dan gangguan visuospasial sebesar $29.8 \%$.

Atensi sangat berhubungan dengan fungsi eksekutif, mengingat pengaturan atensi dan fungsi 
eksekutif melalui sirkuit yang sama, yaitu sirkuit dorsolateral prefrontal. Atensi juga dapat dibedakan menjadi atensi sederhana dan atensi kompleks yang penilaiannya mencakup penilaian fungsi eksekutif di saat bersamaan. Pada penderita PP stadium awal mungkin didapatkan gangguan pada atensi kompleks, tetapi atensi sederhana baru akan dijumpai pada penderita PDD. ${ }^{13}$

Gangguan visuospasial pada penderita PP dihubungkan dengan disfungsi korteks posterior. Berbagai penelitian menunjukkan bahwa skor uji visuoperseptual dan visuospasial penderita PP lebih rendah dari orang normal seusianya. ${ }^{21}$ Lebih jauh lagi, gangguan visuopersepsi dan adanya halusinasi visual meningkatkan risiko perkembangan PD-MCI menjadi PDD. Pada awalnya gangguan visuospasial dikaitkan dengan gangguan motorik penderita PP, tetapi kemudian diketahui bahwa visuospasial pada penderita PP terganggu dan tidak terkait gangguan motorik. ${ }^{13,20}$

Gangguan memori pada penelitian ini didapatkan sebesar 46.8\%. Gangguan memori merupakan gangguan neurokognitif yang paling umum dijumpai pada populasi lansia umum. Penelitian oleh Broeders dkk. (2013) pada penderita PP menunjukkan bahwa gangguan memori merupakan gangguan yang paling banyak dijumpai, dan bahwa gangguan memori sebelumnya merupakan prediktor terjadinya gangguan neurokognitif lebih lanjut pada penderita PP yang baru terdiagnosis. ${ }^{6}$ Penelitian-penelitian lain menyebutkan pada penderita PP fungsi memori didapatkan terganggu setelah fungsi eksekutif terganggu. Fungsi memori yang paling awal terganggu pada PP adalah immediate dan delayed memory, sementara remote memory akan terganggu saat sudah mencapai tahap demensia. Memori implisit juga mulai menurun pada stadium awal PP. ${ }^{13}$

Gangguan bahasa merupakan gangguan yang paling sedikit dijumpai pada penelitian ini, hanya didapatkan pada $10.8 \%$ dari keseluruhan subjek. Hal ini sesuai dengan penelitian-penelitian sebelumnya di mana gangguan bahasa pada penderita PP masih diperdebatkan. Beberapa penelitian mengidentifikasi gangguan bahasa sebagai gangguan minor tersendiri pada PP, sementara yang lain menyatakan gangguan bahasa bukan merupakan gangguan tersendiri. Alasannya adalah penilaian fungsi bahasa seperti phonemic verbal fluency test mengandung komponen penilaian fungsi eksekutif. ${ }^{13}$

Penelitian ini juga mencantumkan gejala motorik dominan yang diderita oleh subjek. Hal ini sesuai dengan beberapa teori yang menyebutkan bahwa gangguan motorik berhubungan dengan gangguan fungsi kognitif pada penderita PP, terutama instabilitas postural. Menurut Hausdorff dkk. (2003) defisit atensi menyebabkan perubahan besar pada gaya jalan dan stabilitas postural. Gangguan fungsi eksekutif juga didapatkan mempengaruhi integrasi informasi sensorik dan perencanaan motorik yang dibutuhkan untuk mempertahankan keseimbangan. ${ }^{23}$ Penelitian pada populasi geriatri tanpa PP menemukan bahwa adanya hubungan antara gangguan fungsi kognitif, terutama atensi dan fungsi eksekutif dengan kejadian jatuh. Hal ini dihubungkan dengan gangguan respon inhibisi dan respon terhadap stimulus distraksi akibat gangguan atensi dan fungsi eksekutif. ${ }^{24}$

\section{Simpulan}

Berdasarkan hasil penelitian dari rumah sakit rujukan di Kota Denpasar didapatkan lebih dari setengah penderita PP di Kota Denpasar mengalami gangguan fungsi kognitif. Profil dasar demografis didapatkan sebagian besar subjek yang mengalami gangguan kognitif merupakan laki-laki, usia lebih dari 60 tahun, berpendidikan tinggi, dan bekerja di sektor formal. Karakteristik dasar subjek dan karakteristik gejala PP pada penelitian ini sesuai dengan penelitian-penelitian serupa sebelumnya. Domain neurokognitif yang paling banyak terganggu adalah fungsi eksekutif, sesuai dengan penelitian dan teori gangguan fungsi kognitif pada PP sebelumnya. Deteksi dini gangguan neurokognitif pada penderita PP perlu dilakukan di pelayanan kesehatan baik primer, sekunder, maupun tersier untuk meningkatkan kualitas hidup penderita PP.

\section{Ucapan Terima kasih}

Ucapan terima kasih kepada dr. Ni Ketut Candra Wiratmi, Sp.S dan seluruh pihak yang telah membantu penelitian ini di RSUP Sanglah Denpasar dan RSUD Wangaya Denpasar. 


\section{Konflik Kepentingan}

Tidak ada konflik kepentingan dalam penelitian ini.

\section{Daftar Rujukan}

1. Jankovic J. Parkinson's disease: Clinical features and diagnosis. J Neurol Neurosurg Psychiatry. 2008;79(4):368-76.

2. DeMaagd G, Philip A. Parkinson's Disease and Its Management: Part 1: Disease Entity, Risk Factors, Pathophysiology, Clinical Presentation, and Diagnosis. P T [Internet]. 2015;40(8):504 32. Tersedia pada: http://www.ncbi.nlm.nih.gov/ pubmed/26236139\%5Cnhttp://www.pubmedcen tral.nih.gov/articlerender.fcgi?artid=PMC45175 $\underline{33}$

3. Yang Y, Tang B, Guo J. Parkinson' s Disease and Cognitive Impairment. 2016;2016.

4. Akdag B, Telci EA, Cavlak U. Factors affecting cognitive function in older adults: A turkish sample. Int J Gerontol. 2013.

5. Lin $\mathrm{CH}, \mathrm{Wu} \mathrm{RM}$. Biomarkers of cognitive decline in Parkinson's disease. Park Relat Disord [Internet]. 2015;21(5):431-43. Tersedia pada: $\quad$ http://dx.doi.org/10.1016/j.parkreldis. 2015.02.010

6. Broeders M, Velseboer DC, de Bie R, Speelman JD, Muslimovic D, Post B, et al. Cognitive change in newly-diagnosed patients with Parkinson's disease: a 5-year follow-up study. J Int Neuropsychol Soc. 2013.

7. Pedersen KF, Larsen JP, Tysnes O-B, Alves G. Prognosis of mild cognitive impairment in early Parkinson disease: the Norwegian ParkWest study. JAMA Neurol. 2013.

8. Aarsland D, Andersen K, Larsen JP, Lolk A, Nielsen H, Kragh-Sørensen P. Risk of dementia in Parkinson's disease: a community-based, prospective study. Neurology. 2001.

9. Buter TC, van den Hout A, Matthews FE, Larsen JP, Brayne C, Aarsland D. Dementia and survival in parkinson disease: A 12-year population study. Neurology. 2008.

10. Ismawati; Muis, A; Akbar, M; Goysal, Y; Kaelan CS. Hubungan Derajat Klinis dan Gangguan Kognitif pada Penderita Parkinson dengan Menggunakan MOCA-INA [Internet]. Makassar; 2013. Tersedia pada: http://repos itory.unhas.ac.id/bitstream/handle/123456789/9
625/HubunganDerajatKlinis.pdf? sequence $=1$

11. Tarukbua FF, Tumewah R, PS JM. Gambaran fungsi kognitif penderita parkinson di Poliklinik Saraf RSUP Prof. Dr. R. D. Kandou Manado. eCliniC. 2016.

12. Adhayani, F; Listyaningrum, D; Sjahrir H. Gangguan Kognitif Penderita Penyakit Parkinson. Neurona [Internet]. 2014;31(2). Tersedia pada: http://www.neurona.web.id /paper-detail.do?id=901

13. Watson GS, Leverenz JBJB. Profile of Cognitive Impairment in Parkinson's Disease. Brain Pathol [Internet]. 2010;20(3):640-645. Tersedia pada: http://onlinelibrary.wiley .com/doi/10.1111/j.1750-3639.2010.00373.x/

full\%0Ahttp://www.pubmedcentral.nih.gov/artic lerender.fcgi?artid $=3049172 \&$ tool $=$ pmcentrez $\& \mathrm{r}$ endertype $=$ abstract

14. Kalia L V., Lang AE. Parkinson's disease. Lancet [Internet]. 2015;386(9996):896-912. Tersedia pada: http://dx.doi.org/10.1016/ S01406736(14)61393-3

15. Sterling NW, Lichtenstein M, Lee E, Lewis MM, Eslinger PJ, Du G, et al. Higher Plasma LDL-Cholesterol is Associated with Preserved Executive and Fine Motor Functions in Parkinson's Disease. Aging Dis [Internet]. 2016;7(3):237-45. Tersedia pada: http://www. aginganddisease.org/EN/volumn/volumn_3867.s html

16. Uc EY, McDermott MP, Marder KS, Anderson SW, Litvan I, Como PG, et al. Incidence of and risk factors for cognitive impairment in an early parkinson disease clinical trial cohort. Neurology. 2009;73(18):1469-77.

17. Silalahi PY. Korelasi Gangguan Fungsi Kognitif dengan Stadium Penyakit Parkinson. Udayana University; 2012.

18.Huang Y-C, Wu S-T, Lin J-J, Lin C-C, Kao CH. Prevalence and Risk Factors of Cognitive Impairment in Parkinson Disease. Medicine (Baltimore) [Internet]. 2015;94(17):e782. Tersedia pada: http://content.wkheal th.com/linkback/openurl?sid=WKPTLP:landing 
page \&an $=00005792-201505010-00031$

19.Biundo R, Weis L, Antonini A. Cognitive decline in Parkinson's disease: the complex picture. npj Park Dis [Internet]. 2016;2(1):16018. Tersedia pada: http://www. nature. com/articles/npjparkd201618

20. Adwani S, Yadav R, Kumar K, Chandra S, Pal P. Neuropsychological profile in early Parkinson's disease: Comparison between patients with right side onset versus left side onset of motor symptoms. Ann Indian Acad Neurol. 2016.

21. Janvin CC, Larsen JP, Aarsland D, Hugdahl K. Subtypes of mild cognitive impairment in
Parkinson's disease: Progression to dementia. Mov Disord. 2006.

22. Hausdorff JM, Balash J, Giladi N. Effects of Cognitive Challenge on Gait Variability in Patients with Parkinson's Disease. J Geriatr Psychiatry Neurol. 2003.

23. Barbosa AF, Chen J, Freitag F, Valente D, Souza CDO, Voos MC, et al. Marcha, postura e cognição na doença de Parkinson. Dement e Neuropsychol. 2016;10(4):280-6.

24. Holtzer R, Verghese J, Xue X, Lipton RB. Cognitive processes related to gait velocity: Results from the Einstein aging study. Neuropsychology. 2006. 